\title{
Insulin therapy refusal among type II diabetes mellitus patients in Kubang Pasu district, Kedah, Malaysia
}

\author{
Wei Leong $\underline{\text { Tan }}^{1}$, MD, Siti Fairus Asahar ${ }^{2}$, MD, Noor Liani Harun³, MBBS
}

INTRODUCTION Diabetes mellitus is a rising non-communicable disease in Malaysia. Insulin therapy refusal is a challenge for healthcare providers, as it results in delayed insulin initiation. This study was conducted to determine the prevalence of insulin therapy refusal and its associated factors.

METHODS This cross-sectional study was conducted at seven public health clinics in Kubang Pasu district of Kedah, Malaysia, from March to October 2012. A newly developed and validated questionnaire was used and participants were selected via systematic random sampling. Only patients diagnosed with type II diabetes mellitus (T2DM) and under the public health clinic care in Kubang Pasu were included in the study. Multiple logistic regression was used to study the association between insulin therapy refusal and its associated factors.

RESULTS There were 461 respondents and the response rate was $100 \%$. Among these 461 patients with T2DM, 74.2\% refused insulin therapy. The most common reason given for refusal was a lack of confidence in insulin injection (85.4\%). Multiple logistic regression revealed that respondents who had secondary education were $55.0 \%$ less likely to refuse insulin therapy than those who had primary education or no formal education (adjusted odds ratio [OR] 0.45, 95\% confidence interval $[\mathrm{Cl}] 0.25-0.82, \mathrm{p}=0.009)$. There was also a significant inverse association between glycated haemoglobin (HbA1c) level and insulin therapy refusal (adjusted OR 0.87, 95\% $\mathrm{Cl} 0.76-1.00, \mathrm{p}=0.047$ ).

CONCLUSION Insulin therapy refusal is common in Kubang Pasu. Educational status and HbA1c level should be taken into consideration when counselling patients on insulin therapy initiation.

Keywords: insulin therapy refusal, Kedah, Malaysia, type II diabetes mellitus

\section{INTRODUCTION}

The prevalence of diabetes mellitus in Malaysia has been increasing. According to the 2011 National Health and Morbidity Survey, the prevalence of diabetes mellitus in individuals aged $\geq 18$ years had increased from $11.6 \%$ in 2006 to $15.2 \%$ in $2011 .{ }^{(1)}$ In a keynote address by the Malaysian Director General of Health in 2012, the prevalence of diabetes mellitus was projected to increase by more than $20 \%$ in 2020. ${ }^{(2)}$ The Diabetes Clinical Audit (2009-2011) from the National Diabetes Registry of Malaysia reported that in 2011, $17.1 \%$ of patients with diabetes mellitus were on insulin, while $13.4 \%$ were on oral hypoglycaemic agents and insulin. ${ }^{(3)}$

With the increasing prevalence of diabetes mellitus in Malaysia, one of the main challenges in managing diabetic patients who have suboptimal control will be insulin therapy refusal. Although insulin therapy has been demonstrated to be efficacious, its initiation is often delayed in Malaysia. A study conducted by NurAzmiah et al in Kuala Lumpur and Putrajaya, two of the three federal territories of Malaysia, revealed that the reasons for psychological insulin resistance included personal failure, pain associated with insulin injection and fear of problematic hypoglycaemia. ${ }^{(4)}$

The commencement of insulin therapy has always been a mutual decision between the healthcare provider and the patient. The decision-making process is affected by factors that involve both parties. Therefore, the aim of the present study was to determine the prevalence of insulin therapy refusal (from the patient's perspective), as well as to identify the factors associated with insulin therapy refusal. As compared to the study cohort in NurAzmiah et al's study, ${ }^{(4)}$ our study population consists of patients from a rural area. These patients would have perceptions about healthcare and behaviours that are distinct from those living in the federal territories. Most of the previous studies from Malaysia and Singapore involved patient populations that consisted of well-urbanised city dwellers. ${ }^{(4,5)}$

\section{METHODS}

A cross-sectional study was conducted at all public health clinics in the Kubang Pasu district of Kedah, Malaysia, from March to October 2012. The sample size was determined using a simple formula ${ }^{(6)}$ with $50.7 \%$ expected prevalence of insulin therapy refusal, ${ }^{(4)} 95 \%$ confidence interval $(\mathrm{Cl})$ and $5 \%$ precision. The calculated sample size required was 461 respondents after a $20 \%$ allowance for non-respondents. Only patients diagnosed with type II diabetes mellitus (T2DM) and managed under the public health clinic care of Kubang Pasu were included in this study. Systematic random sampling was conducted in all the seven public health clinics in Kubang Pasu to select participants; they were selected while attending a clinic session for follow-up of their T2DM (every fifth patient was selected, according to their waiting number).

The questionnaire used in this study was developed with reference to the study by NurAzmiah et al. ${ }^{(4)}$ It was tested in a pilot study involving 20 patients; the pilot study was conducted

${ }^{1}$ Clinical Research Centre of Kedah, ${ }^{2}$ Air Hitam Health Clinic, ${ }^{3}$ Tunjang Health Clinic, Kedah, Malaysia

Correspondence: Dr Tan Wei Leong, Medical Officer, Clinical Research Centre, Sultanah Bahiyah Hospital, KM 6, Jalan Langgar, 05460, Alor Setar, Kedah, Malaysia. alextanwl@yahoo.com 
in a public health clinic in Kubang Pasu. The Cronbach's alpha value for the questionnaire was 0.745 . Content validation of the questionnaire was done by two family medicine specialists and two public health specialists in Kubang Pasu.

Data was descriptively analysed using the IBM Statistical Package for the Social Sciences version 20.0 (IBM Corp, Armonk, NY, USA). Multiple logistic regression was used to study the factors associated with insulin therapy refusal. A p-value $<0.05$ was considered statistically significant. This study was approved by the Medical Research Ethics Committee of Malaysia and was registered under National Medical Research Registry, Malaysia.

\section{RESULTS}

The response rate in this study was $100 \%$. The mean age of the 461 respondents was $56.4 \pm 9.6(23-80)$ years. The majority of the respondents were Malay (94.6\%), female (70.3\%), unemployed $(65.1 \%)$, and had only primary education or no formal education (54.2\%). The mean duration of T2DM was $5.3 \pm 3.6$ years and the mean glycated haemoglobin ( $\mathrm{HbA} 1 \mathrm{c})$ level was $8.79 \% \pm 2.19 \%$. Among the 461 respondents, $85.7 \%$ had uncontrolled T2DM and only $17.6 \%$ were on insulin therapy. The prevalence of insulin therapy refusal was $74.2 \%$. The reasons for insulin therapy refusal are listed in Table I.

Simple logistic regression was used to analyse the association between insulin therapy refusal and several factors (Table II). Three factors were found to be significantly associated with insulin therapy refusal, namely HbA1c level ( $p<0.001)$, duration of T2DM $(p=0.001)$, and monthly income $(p=0.017)$. HbA1c level was inversely related to insulin therapy refusal; an increment of $1.0 \%$ in $\mathrm{HbA} 1 \mathrm{c}$ level resulted in a reduction in insulin therapy refusal by about $28.0 \%$ (crude odds ratio [OR] $0.72,95 \% \mathrm{Cl} 0.65-0.80, \mathrm{p}<0.001)$. In the case of duration of T2DM, we found that an increase of one year in the duration of T2DM reduced insulin therapy refusal by $9.0 \%$ (crude OR 0.91 , $95 \% \mathrm{Cl}$ 0.86-0.96, $\mathrm{p}=0.001$ ). Respondents with a monthly income of RM $801-3,000$ were found to be $44.0 \%$ less likely to refuse insulin therapy as compared to respondents who earned $\leq$ RM 800 monthly (crude OR 0.56, 95\% Cl 0.36-0.87, p = 0.017).

Since we could not control for other factors in the simple logistic regression analysis, multiple logistic regression was used to further investigate the factors associated with insulin therapy refusal (Table III). Using multiple logistic regression, we found that only $\mathrm{HbA1c}$ level and educational status were significantly associated with insulin therapy refusal. $\mathrm{HbA} 1 \mathrm{c}$ level was inversely related to insulin therapy refusal. After controlling for other variables, we found that an increment of $1.0 \%$ in $\mathrm{HbA} 1 \mathrm{c}$ level reduced insulin therapy refusal by $13 \%$ (adjusted OR 0.87, 95\% Cl 0.76-1.00, p = 0.047). In the case of education, respondents who had at least secondary education were found to be $55.0 \%$ less likely to refuse insulin therapy as compared to those who had only primary education or no formal education (adjusted OR 0.45, 95\% Cl 0.25-0.82, $\mathrm{p}=0.026$ ).

\section{DISCUSSION}

In the present study, $74.2 \%$ of the patients with T2DM who were seen in public clinics in Kubang Pasu refused the insulin
Table I. Reasons for insulin therapy refusal among the patients with type II diabetes mellitus in Kubang Pasu $(n=342)$.

\begin{tabular}{lcc}
\hline \multirow{2}{*}{ Reason for insulin therapy refusal } & \multicolumn{2}{c}{ No. (\%) } \\
\cline { 2 - 3 } & Agree & Disagree \\
\hline Lack of confidence in insulin injection & $292(85.4)$ & $50(14.6)$ \\
Misconception that insulin therapy & $247(72.2)$ & $95(27.8)$ \\
can lead to renal failure and blindness & & \\
Restrictiveness in daily life and work & $247(72.2)$ & $95(27.8)$ \\
Insulin commencement indicates a & $242(70.8)$ & $100(29.2)$ \\
serious stage of diabetes mellitus & & \\
Feeling of failure to control diabetes & $236(69.0)$ & $106(31.0)$ \\
mellitus & & \\
Fear of pain during injection & $233(68.1)$ & $109(31.9)$ \\
Fear of hypoglycaemia & $204(59.6)$ & $138(40.4)$ \\
Cost (i.e. financial burden) & $201(58.8)$ & $141(41.2)$ \\
Lack of support from family members & $169(49.4)$ & $173(50.6)$ \\
Vision problem & $124(36.3)$ & $218(63.7)$ \\
Fear of scarring at area of injection & $74(21.6)$ & $268(78.4)$ \\
Insulin injection is perceived to be & $60(17.5)$ & $282(82.5)$ \\
embarrassing & & \\
\hline
\end{tabular}

Table II. Results of the simple logistic regression analysis for demographic factors associated with insulin therapy refusal.

\begin{tabular}{|c|c|c|c|c|}
\hline Variable & Crude OR & $95 \% \mathrm{Cl}$ & $\chi^{2}(\mathrm{df})^{*}$ & p-value* \\
\hline Age (yr) & 1.02 & $1.00-1.04$ & $3.2(1)$ & 0.074 \\
\hline HbA1c (\%) & 0.72 & $0.65-0.80$ & $43.0(1)$ & $<0.001$ \\
\hline Duration of T2DM & 0.91 & $0.86-0.96$ & $11.3(1)$ & 0.001 \\
\hline Gender & & & & 0.430 \\
\hline Male & 1.21 & $0.76-0.96$ & $0.62(1)$ & \\
\hline Female & 1.00 & - & - & \\
\hline Ethnicity & & & & 0.226 \\
\hline Malay & 0.53 & $0.18-1.58$ & $1.46(1)$ & \\
\hline Non-Malay & 1.00 & - & - & \\
\hline Marital status & & & $0.01(2)$ & 0.994 \\
\hline Single & 0.93 & $0.24-3.56$ & $0.01(1)^{+}$ & $0.912^{+}$ \\
\hline Widowed & 1.01 & $0.48-2.14$ & $0.00(1)^{+}$ & $0.984^{+}$ \\
\hline Married & 1.00 & - & - & - \\
\hline Employment status & & & & 0.727 \\
\hline Unemployed & 0.93 & $0.60-1.44$ & $0.12(1)$ & \\
\hline Employed & 1.00 & - & - & \\
\hline Educational level & & & $3.34(2)$ & 0.188 \\
\hline Tertiary & 0.63 & $0.23-1.72$ & $0.83(1)^{+}$ & $0.363^{+}$ \\
\hline Secondary & 0.68 & $0.45-1.05$ & $3.02(1)^{+}$ & $0.082^{+}$ \\
\hline Primary & 1.00 & - & - & - \\
\hline Monthly income (RM) & & & $8.00(2)$ & 0.017 \\
\hline $801-3,000$ & 0.56 & $0.36-0.87$ & $6.56(1)^{+}$ & $0.010^{+}$ \\
\hline$>3,000$ & 0.45 & $0.19-1.04$ & $3.52(1)^{+}$ & $0.061^{+}$ \\
\hline$\leq 800$ & 1.00 & - & - & - \\
\hline
\end{tabular}

* Calculated using likelihood ratios test. †Calculated using Wald test. $\mathrm{Cl}$ : confidence interval; df: degrees of freedom; HbA1c: glycated haemoglobin; OR: odds ratio; T2DM: type II diabetes mellitus

therapy prescribed by healthcare providers. This percentage is higher than those of several studies. In the study by NurAzmiah et al, $50.7 \%$ of the respondents refused the prescribed insulin. ${ }^{(4)}$ In a study conducted by Wong et al in Singapore, $70.6 \%$ of 
Table III. Results of the multiple logistic regression performed to determine the factors associated with insulin therapy refusal.

\begin{tabular}{lcccc}
\hline Variable & Adjusted OR & $\mathbf{9 5 \%} \mathbf{C l}$ & $\chi^{\mathbf{2}}(\mathbf{d f})^{*}$ & p-value $^{*}$ \\
\hline HbA1c (\%) & 0.87 & $0.76-1.00$ & $3.95(1)$ & 0.047 \\
Duration of T2DM & 1.01 & $0.93-1.10$ & $0.07(1)$ & 0.792 \\
Educational level & & & $7.28(2)$ & 0.026 \\
$\quad$ Tertiary & 0.52 & $0.13-2.11$ & $0.83(1)^{+}$ & $0.361^{+}$ \\
$\quad$ Secondary & 0.45 & $0.25-0.82$ & $6.89(1)^{+}$ & $0.009^{+}$ \\
Primary & 1.00 & - & - & \\
Monthly income & & & $2.81(2)$ & 0.245 \\
(RM) & & & & \\
$\quad 801-3,000$ & 0.58 & $0.30-1.12$ & $2.67(1)$ & $0.103^{+}$ \\
$>3,000$ & 0.84 & $0.19-3.78$ & $0.06(1)$ & $0.815^{+}$ \\
$\leq 800$ & 1.00 & - & - & - \\
\hline
\end{tabular}

*Calculated using likelihood ratios test. †Calculated using Wald test $\mathrm{Cl}$ : confidence interval; $\mathrm{df}$ : degrees of freedom; HbA1c: glycated haemoglobin; OR: odds ratio; T2DM: type II diabetes mellitus

the patients expressed unwillingness to use insulin therapy. ${ }^{(5)} \mathrm{A}$ study conducted on Bangladeshi patients in East London who had poorly controlled T2DM showed that $42.5 \%$ refused insulin therapy when it was first prescribed.(7) Polonsky et al found a relatively low prevalence of insulin therapy refusal (i.e. $28.2 \%$ ) in their study on psychological insulin resistance in patients with T2DM. ${ }^{(8)}$ Compared to these studies, which were conducted in urban settings (where healthcare services and health promotion are abundant), the present study was conducted in a rural setting (where health promotion is limited and patient acceptance of health information might be lower). Table IV compares the population profile of our study with those of studies by NurAzmiah et $\mathrm{al}^{(4)}$ and Polonsky et al. ${ }^{(8)}$

The majority of the patients in the present study who refused insulin therapy responded that they did so because they lacked confidence in injecting insulin (85.4\%). Similarly, Wong et al found that $70.6 \%$ of Singapore patients who were unwilling to use insulin had the fear of not being able to inject insulin correctly. ${ }^{(5)}$ Polonsky et al also reported that low self-efficacy in handling insulin therapy was one of the significant negative attitudes that led to insulin therapy refusal in California, North Carolina, Oregon and Minnesota. ${ }^{(8)}$ NurAzmiah et al reported that $35.9 \%$ of their patients expressed low self-efficacy. ${ }^{(4)}$ The higher percentage of low self-efficacy in injecting insulin among the respondents of the present study could be due to a lack of counselling sessions or ineffective counselling by healthcare providers. The educational status of the respondents may also have affected the effectiveness of the counselling sessions conducted.

The second most common reason for insulin therapy refusal in the present study was the misconception that insulin therapy may lead to renal failure and blindness (72.2\%). NurAzmiah et al reported that $15.1 \%$ of patients with psychological insulin resistance believed that insulin could cause problems such as blindness. ${ }^{(4)}$ Polonsky et al reported that $16.7 \%$ of the unwilling patients in their study believed that insulin could cause harm such as blindness. ${ }^{(8)}$ In a study by Lee et $\mathrm{al}^{\left({ }^{(9)}\right.}$ in which the opinions of 38 healthcare professionals on barriers to insulin initiation were collected, insulin was reported to be perceived by patients as being lethal, a punishment or a cause of sexual dysfunction. In the same study, these healthcare professionals also cited lack of knowledge and low self-efficacy as barriers to insulin therapy initiation. ${ }^{(9)}$ Khan et al reported a similar finding, with patients having the belief that insulin therapy could lead to early death. ${ }^{(7)}$ When compared to the studies conducted by NurAzmiah et $\mathrm{a}^{(4)}$ and Polonsky et $\mathrm{al},{ }^{(8)}$ the higher prevalence of misconceptions about insulin therapy observed in the present study could be due to a lack of diabetes education among the patients with T2DM who live in rural areas (as compared to those who live in urban areas). With limited accurate education on T2DM and its treatment, patients with T2DM living in rural areas would tend to accept wrong facts and misleading information from friends and relatives.

In the present study, patients who refused insulin therapy also felt that insulin therapy would restrict their daily life and work $(72.2 \%)$. Polonsky et al found that $56.1 \%$ of their patients believed that insulin therapy would restrict their lives and make it harder for them to travel or eat out. ${ }^{(8)}$ NurAzmiah et al also found that $42.4 \%$ of their patients with psychological insulin resistance thought that they would not have enough time for regular doses of insulin. ${ }^{(4)}$ Wong et al showed that $66.8 \%$ of the patients who refused insulin therapy believed that insulin therapy would make it difficult for them to fulfil their responsibilities at work and at home. ${ }^{(5)}$

NurAzmiah et al found that diabetic control was significantly associated with the patient's willingness to use insulin $(p=0.022) .{ }^{(4)}$ In the present study, we found that $\mathrm{HbA} 1 \mathrm{c}$ level was both significantly and inversely related to insulin therapy refusal. An increment of $1.0 \%$ in $\mathrm{HbA} 1 \mathrm{c}$ level resulted in the reduction of insulin therapy refusal by $13.0 \%$. In a study conducted by Lam et al in Singapore, patients who were unwilling to initiate insulin therapy had a lower mean $\mathrm{HbA1c}$ level as compared to those who were willing. ${ }^{(10)}$

In Lam et al's study, patients who had a higher educational background were found to have a less negative appraisal score for insulin therapy (based on discrete analysis). ${ }^{(10)}$ In the present study, we found that patients who had at least a secondary education were $55.0 \%$ less likely to refuse insulin therapy as compared to patients who had only primary education or no formal education. This finding is in agreement with that of Wong et al's study, which also revealed that a tertiary level of education was associated with a greater willingness to use insulin (OR 3.3, 95\% Cl 1.8-6.1). ${ }^{(5)}$ Such findings are not surprising, as patients with a better educational background are expected to be more receptive toward knowledge on diabetes mellitus and insulin therapy. In constrast, the study by NurAzmiah et al showed no association between educational level and willingness to use insulin. ${ }^{(4)}$

The present study was not without limitations. Firstly, healthcare provider-related factors were not explored. The inclusion criteria used in this study was also relatively broad. It included patients who had optimal diabetic control, newly diagnosed patients with T2DM and patients who were already on insulin therapy. Patients in the first two groups may not require insulin therapy yet, while patients in the last group may 'self- 
Table IV. Comparison of the profiles of the populations used in NurAzmiah et al's study, ${ }^{(4)}$ Polonsky et al's study(8) and the present study.

\begin{tabular}{|c|c|c|c|}
\hline Profile & NurAzmiah et al $^{(4)}$ & Polonsky et $\mathrm{al}^{(8)}$ & Present study \\
\hline Mean age (yr) & 54.5 & 57.4 & 56.4 \\
\hline Dominant ethnicity & Malay $(71.0 \%)$ & Non-Hispanic whites (53.7\%) & Malay $(94.6 \%)$ \\
\hline Dominant gender & Male $(57.2 \%)$ & Female $(65.8 \%)$ & Female $(70.3 \%)$ \\
\hline Dominant educational status & $\begin{array}{l}\text { At least secondary } \\
\text { education }(85.4 \%)\end{array}$ & Not available & $\begin{array}{l}\text { Primary education or no } \\
\text { formal education ( } 54.2 \%)\end{array}$ \\
\hline Dominant employment status & Unemployed (44.5\%) & Not available & Unemployed (65.1\%) \\
\hline Location of study & $\begin{array}{l}\text { Urban area: Kuala } \\
\text { Lumpur; Putrajaya, } \\
\text { Malaysia }\end{array}$ & $\begin{array}{l}\text { Urban area: California; North } \\
\text { Carolina; Oregon; Minnesota, } \\
\text { USA }\end{array}$ & $\begin{array}{l}\text { Rural area: Kubang Pasu, } \\
\text { Malaysia }\end{array}$ \\
\hline
\end{tabular}

select' to accept insulin therapy. Finally, the systematic random sampling that was employed in this study is not as statistically robust as simple random sampling. We recommend that simple random sampling be used in future studies that aim to evaluate the prevalence of insulin therapy refusal and its associated factors. Future studies should also employ narrower inclusion criteria, such that only patients with suboptimal T2DM control (despite optimal doses of oral hypoglycaemic agents) and patients with T2DM for $>6$ months are included.

Patients with T2DM, especially those from a rural setting or with a low educational level, should be adequately educated on the disease and its complications. Through adequate education, the patients' confidence in handling insulin injections may increase and their understanding of the benefits of insulin therapy may also be enhanced. As one session of counselling may not be sufficient to convince patients to accept insulin therapy, healthcare providers should be prepared to conduct multiple counselling sessions in order to get their patients to accept insulin therapy. Some strategies that may help promote acceptance of insulin therapy include inviting a relative or friend of the patient who is on insulin therapy to participate in counselling sessions, group therapy and regular injection demonstrations. Better outreach and health promotion in the community should also be stressed by the public health sector. As misconceptions on insulin therapy are common in rural communities, health promotion on T2DM and the benefits of insulin therapy should be stepped up in these areas. Healthcare providers need to be equipped to tackle patients' concerns and confusion regarding insulin therapy. With adequate knowledge, misconceptions and inaccurate understanding of T2DM and insulin therapy can thus be addressed effectively. Further studies on how healthcare provider-related factors contribute to insulin therapy can be conducted to supplement the findings of the present study.

In summary, insulin therapy refusal was common among the patients with T2DM in Kubang Pasu; the prevalence of insulin therapy refusal was $74.2 \%$. The most common reasons for insulin therapy refusal among the patients was a lack of confidence in injecting insulin, followed by misconceptions about insulin therapy. $\mathrm{HbA} 1 \mathrm{c}$ level and educational status were found to be significantly associated with insulin therapy refusal. Therefore, these two factors should be taken into consideration by healthcare providers when conducting counselling sessions on insulin therapy initiation. The present study was conducted in a rural community, where the prevalence of insulin therapy refusal was found to be much higher compared to that in similar studies conducted in urban settings. The difference in educational status may present as a learning barrier, and contribute to the patients' lack of confidence and misconception about insulin. Healthcare providers managing patients with T2DM in rural settings such as the Kubang Pasu district would need to address these factors.

\section{ACKNOWLEDGEMENTS}

We thank the Director General of Health, Malaysia, for permission to publish this paper. We also would like to express our gratitude and appreciation to all the participants and staff involved for their kind support.

\section{REFERENCES}

1. National Health and Morbidity Survey 2011 - Fact Sheet. Ministry of Health; 2011.

2. Abdul Rahman $\mathrm{H}$. The future of diabetes mellitus in Malaysia. Keynote address. Malaysian Diabetes Educators Society Seminar 2012 April 20.

3. National Diabetes Registry 2009-2012. Putrajaya: Ministry of Health, Malaysia, 2013.

4. NurAzmiah Z, Zulkarnain AK, Tahir A. Psychological insulin resistance among type II diabetes mellitus patients at public health clinic in Federal Territory of Malaysia. Int Med J Malaysia 2011; 10:1-6.

5. Wong S, Lee J, Ko Y, et al. Perceptions of insulin therapy amongst Asian patients with diabetes in Singapore. Diabet Med 2011; 28:206-11.

6. Daniel WW. Biostatistics: A Foundation for Analysis in the Health Sciences. 7th ed. New York: John Wiley \& Sons, 1999.

7. Khan H, Lasker SS, Chowdhury TA. Prevalence and reasons for insulin refusal in Bangladeshi patients with poorly controlled Type 2 diabetes in East London. Diabet Med 2008; 25:1108-11.

8. Polonsky WH, Fisher L, Guzman S, Villa-Caballero L, Edelman SV. Psychological insulin resistance in patients with type 2 diabetes: the scope of the problem. Diabetes Care 2007; 28:2543-5.

9. Lee YK, Lee PY, Ng CJ. A qualitative study on healthcare professionals' perceived barriers to insulin initiation in a multi-ethnic population. BMC Fam Pract 2012; 13:28.

10. Lam CK, Chong MF, Wong S, Lee J. Perception of insulin therapy in patients with type 2 diabetes mellitus in a primary care center in Singapore. Singapore: National University of Singapore, 2010 